\title{
Chemistry of organopalladium and nickel complexes relevant to catalysis
}

\author{
Akio Yamamoto, Takakazu Yamamoto, and Fumiyuki Ozawa \\ Research Laboratory of Resources Utilization, Tokyo Institute of Technology,
} Nagatsuta, Yokohama, 227, Japan

\begin{abstract}
Fundamental studies on reductive elimination reactions of organonickel and palladium complexes of the types $\mathrm{MR}_{2} \mathrm{~L}_{2}$ and $\mathrm{M}(\mathrm{COR})(\mathrm{OAr}) \mathrm{L}_{2}$ revealed the parallel trend between the reductive eliminations involving the $\mathrm{C}-\mathrm{C}$ and $\mathrm{C}-\mathrm{O}$ bond formation. The reaction of organonickel complexes proceeds mainly via associative mechanism whereas reductive eliminations from many square planar palladium complexes take dissociative pathways. Based on the fundamental studies on reactions of organopalladium complexes with carbon monoxide a new reaction to introduce two $\mathrm{CO}$ groups into an organic compound has been developed. Aryl halides and alkenyl halides are catalytically converted into $\alpha$-keto amides promoted by tertiary phosphinecoordinated palladium complexes in the reaction with $\mathrm{CO}$ and basic secondary amines. $\alpha$-Keto amides produced in the reaction can be used as precursors for syntheses of useful organic compounds including $\alpha$-amino acids, $\alpha$-hydroxy acids, indole and quinoline derivatives. Mechanism for production of $\alpha$-keto amides from aryl halides, $C 0$ and secondary amines has been established to comprise several steps, i.e., oxidative addition of aryl halide to $\mathrm{Pd}(0)$ species, $\mathrm{CO}$ insertion into the $\mathrm{Ar}-\mathrm{Pd}$ bond, $\mathrm{CO}$ coordination to palladium, and nucleophilic attack of amine on the coordinated CO ligand to give carbamoyl-aroyl species which reductively eliminates $\alpha$-keto amides. Steric bulkiness of the secondary amines in attacking on the CO ligand was found to be decisive in determining the selectivity for $\alpha$-keto amide formation. Catalytic $\alpha$-keto ester synthesis using aryl halides, CO, alcohols and tertiary amine also has been achieved. Stoichiometric conversion of alkenes, secondary amines, CO and palladium dichloride into $\beta, \gamma$-unsaturated- $\alpha$-keto amide also has been accomplished.
\end{abstract}

\section{INTRODUCTION}

Complexes of palladium and nickel have proved most useful among other transition metals in promoting specific carbon-carbon, carbon-oxygen and carbon-nitrogen bond formation under mild conditions. Basic strategy for these synthetic reactions involves combination of fundamental processes such as reductive elimination, insertion and external attack of a nucleophile on a coordinated ligand (ref. 1).

$$
\begin{aligned}
& \mathrm{L}_{\mathrm{n}}{ }_{\mathrm{M}}^{\mathrm{R}} \longrightarrow \mathrm{L}_{\mathrm{n}} \mathrm{M}+\mathrm{R}-\mathrm{R} \\
& \mathrm{L}_{\mathrm{n}}{ }_{\mathrm{M}}^{\prime}{ }_{\mathrm{CO}}^{\mathrm{R}} \longrightarrow \mathrm{L}_{\mathrm{n}} \mathrm{M}-\stackrel{\mathrm{O}}{\mathrm{C}}-\mathrm{R} \\
& \mathrm{L}_{\mathrm{n}} \mathrm{M}^{+}-\mathrm{C} \equiv \mathrm{O}+\mathrm{Nu}^{-} \longrightarrow \mathrm{L}_{\mathrm{n}} \mathrm{M}-\mathrm{C}^{\prime \prime}
\end{aligned}
$$

In this paper we wish to review how our basic studies on the elementary steps (1) - (3) led to the finding of a novel and useful catalytic reaction utilizing a palladium complex catalyst for introducing two carbonyl groups into an organic compound. 


\section{REDUCTIVE ELIMINATION INVOLVING C-C BOND FORMATION}

Eq. 1 represents the fundamental concept of the reductive elimination but the actual reaction pathway may vary depending on the metal, ligands, and configuration of the complex involved. Previous studies on the reductive elimination (ref. 2-5) have revealed that reductive elimination of alkyl groups at mutually cis sites in nickel dialkyls proceeds by nondissociative or associative mechanisms.

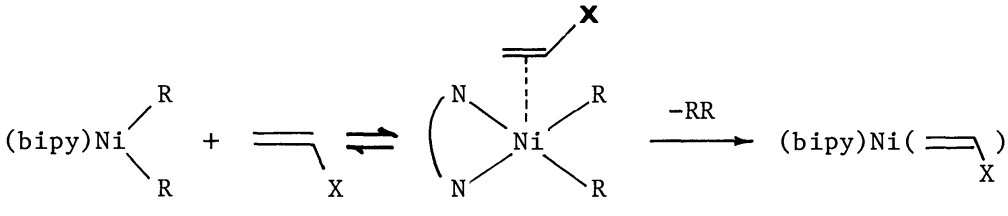

$\mathrm{R}=\mathrm{Me}, \mathrm{Et} \quad \mathrm{X}=$ electron-withdrawing group

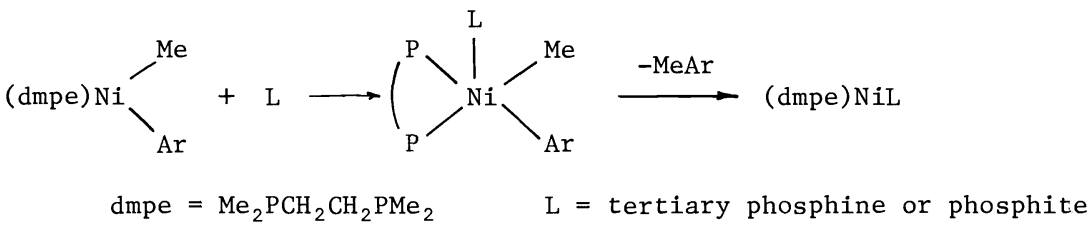

In contrast to the nickel complexes reductive elimination of cis-dialkylpalladium complexes having two tertiary phosphine ligands has been found to proceed by a dissociative mechanism via a T-shaped intermediate ( $r e f .6,7)$ as supported by a theoretical study based on extended Hückel calculations (ref. 8).

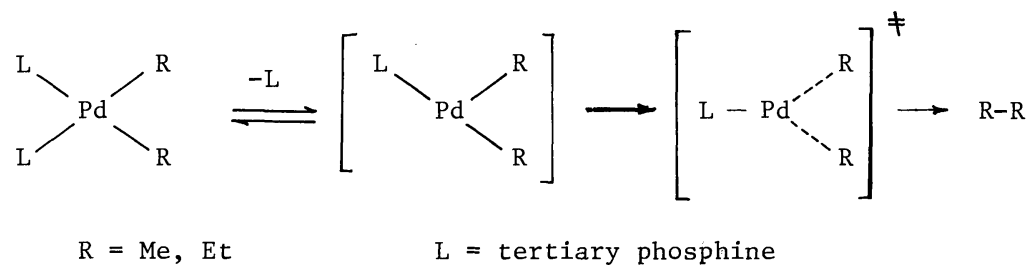

In thermolysis of trans- $\mathrm{PdEt}_{2} \mathrm{~L}_{2}$ on the other hand the main reaction pathway is nondissociative and ethylene and ethane are released in a $1: 1$ ratio (ref. 9).

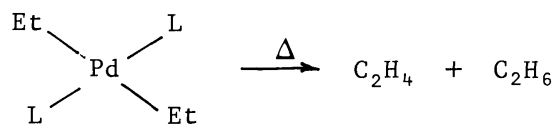

Trans-PdMe $\mathrm{L}_{2}$, for which this thermolysis route involving the $\beta$-hydrogen elimination is not available, is thermolyzed after initial isomerization to the cis isomer which liberates ethane as the reductive elimination product (ref. $6 a, 7$ ).

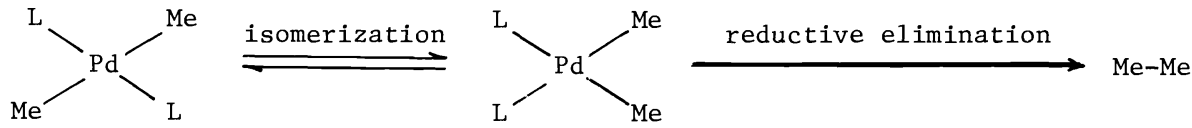

Thus quite similar dialkyl complexes of nickel and palladium show contrasting behavior in their reductive elimination reaction (Note).

Note: However it should be noted here that these results do not entirely exclude the possibility of an associative pathway since the reaction of $\mathrm{PdMe}_{2}$ (dpe) (dpe $=1,2-\mathrm{bis}-$ (diphenylphosphino)ethane) liberates ethane on interaction with carbon monoxide, a $\pi$-acceptor. In this case the dissociative path is not operative by the presence of the strongly coordinating dpe ligand. On the other hand the reaction of cis- $\mathrm{PdMe}_{2} \mathrm{~L}_{2}$ ( $\mathrm{L}=$ mono tertiary phosphine) with CO gives MeCOMe and MeCOCOMe by a dissociative pathway. 


\section{REDUCTIVE ELIMINATION INVOLVING C-O BOND FORMATION}

In contrast to the studies on reductive elimination with the $\mathrm{C}-\mathrm{C}$ bond formation, reductive elimination involving $\mathrm{C}-0$ bond formation has received very little attention. We have previously reported that $\mathrm{C}-0$ bonds in allyl and aryl carboxylates, and carboxylic anhydrides can be readily cleaved on interaction with $\mathrm{Ni}(0)$ and $\mathrm{Pd}(0)$ complexes (ref. $10-15)$.

$$
\begin{aligned}
& \mathrm{L}_{\mathrm{n}} \mathrm{M}+\mathrm{RC}_{0}^{\mathrm{R}-\mathrm{OAr}} \rightleftharpoons \mathrm{L}_{\mathrm{n}}{ }^{\mathrm{Ni}} \overbrace{\mathrm{OAr}}^{\|_{\mathrm{C}}-\mathrm{R}}
\end{aligned}
$$

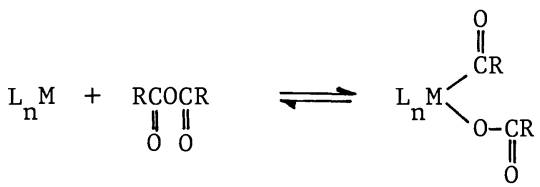

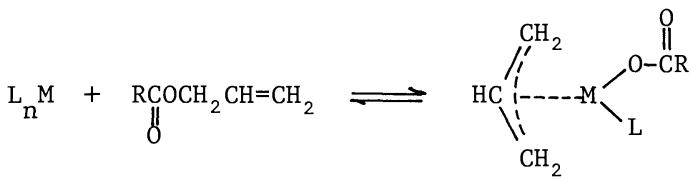

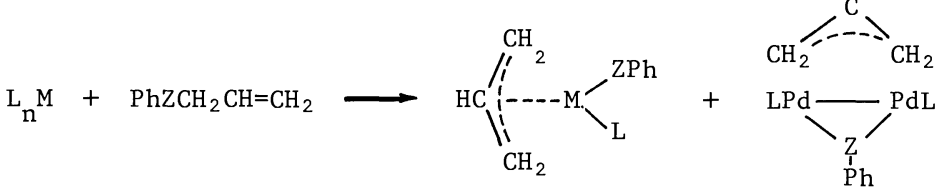

$\mathrm{Z}=0, \mathrm{~S}, \mathrm{Se}$

Many of these $\mathrm{C}-\mathrm{O}$ bond cleavage reactions have been found reversible. Examination of factors influencing the reverse process of eq. 9 revealed the presence of a somewhat parallel trend between the reductive eliminations involving the $\mathrm{C}-\mathrm{C}$ bond formation and those involving the $\mathrm{C}-0$ bond formation of nickel and palladium complexes (ref. 16). The reductive elimination of carboxylic esters from acyl(aryloxy)nickel complexes is accelerated by added $\pi$-acids such as maleic anhydride, acrylonitrile, and $\mathrm{co}$. The result suggests involvement of a fivecoordinate intermediate in the reductive elimination of esters from the nickel complexes.

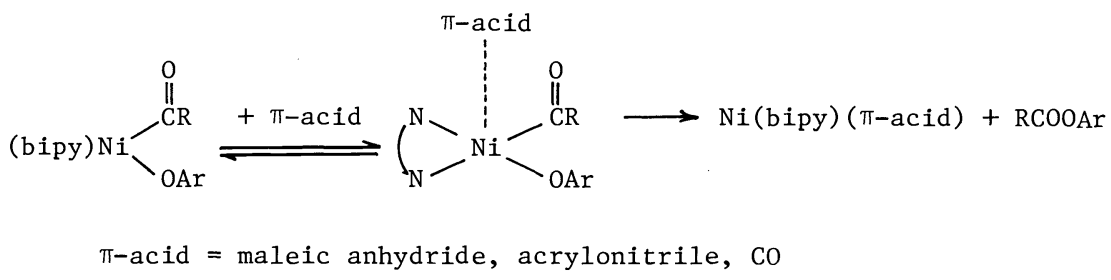

On the other hand no acceleration effect on reductive elimination of aryl carboxylate from trans-Pd $(\mathrm{COMe})\left(\mathrm{OC}_{6} \mathrm{H}_{4} \mathrm{CN}\right)\left(\mathrm{PEt}_{3}\right)_{2} \frac{1}{\sim}$ was observed by addition of m-acids. Addition of $\mathrm{PE} \mathrm{t}_{3}$ to the solution containing $\underset{\sim}{1}$ showed inhibition effect on the reductive elimination of the aryl carboxylate. The result suggests involvement of a dissociative mechanism proceeding through a T-shaped intermediate in the $\mathrm{C}-\mathrm{O}$ bond formation reminiscent of the one assumed in the reductive elimination of alkane from the cis-dialkylpalladium complexes.

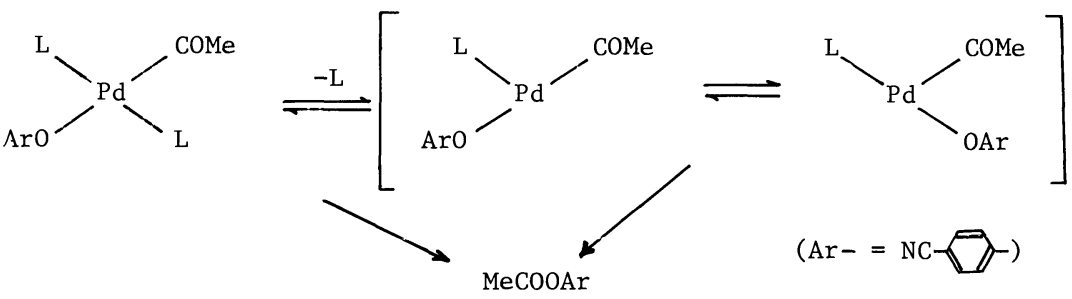

These results suggest involvement of simflar controlling factors in the both reductive eliminations accompanying the $\mathrm{C}-\mathrm{C}$ bond formation and the $\mathrm{C}-\mathrm{O}$ bond formation. 


\section{DOUBLE CARBONYLATION REACTIONS}

In our studies on reactivity of dialkyl and monoalkylpalladium complexes with carbon monoxide we found that $\alpha$-keto amides are formed in addition to amides on treating these complexes with $\mathrm{CO}$ and secondary amines (ref. 17).

$$
\begin{gathered}
\text { cis-PdMe }{ }_{2} \mathrm{~L}_{2}+\mathrm{CO}+\mathrm{R}_{2}^{\prime} \mathrm{NH} \longrightarrow \mathrm{MeCOCONR}_{2}^{\prime}+\text { MeCONR}_{2}^{\prime} \\
\stackrel{\text { trans }}{ }-\mathrm{PdR}(\mathrm{X}) \mathrm{L}_{2}+\mathrm{CO}+\mathrm{R}_{2}^{\prime} \mathrm{NH} \longrightarrow \mathrm{RCOCONR}_{2}^{\prime}+\mathrm{RCONR}_{2}^{\prime} \\
\quad \mathrm{X}=\mathrm{Br}, \mathrm{I}, \mathrm{OAr} \quad \mathrm{L}=\text { tertiary phosphine }
\end{gathered}
$$

Since oxidative addition of aryl halides to a $\operatorname{Pd}(0)$ species is known to give trans $-\operatorname{PdAr}(\mathrm{X}) \mathrm{L}_{2}$, we can couple the reaction 16 with the oxidative addition process to devise a catalytic process for converting aryl halides, secondary amines, and Co into $\alpha$-keto amides (ref. 18,19).

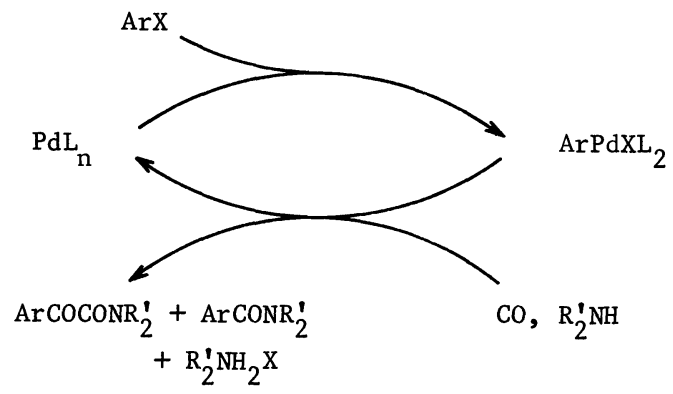

Scheme I Concept of catalytic conversion of aryl halides, CO and secondary amines to $\alpha$-keto amides catalyzed by a palladium complex

The process is versatile and applicable to conversion of halides of various aromatic, heterocyclic, and olefinic compounds.

$$
\mathrm{RX}+2 \mathrm{CO}+2 \mathrm{R}_{2}^{\prime} \mathrm{NH} \stackrel{\mathrm{Pd} \text { catalyst }}{\longrightarrow} \mathrm{RCOCONR} \mathrm{R}_{2}^{\prime}+\mathrm{R}_{2}^{\prime} \mathrm{NH}_{2} \mathrm{X}
$$

Table 1 provides representative examples of yields of $\alpha$-keto amides and amides derived from various aryl and alkenyl halides reacted with $\mathrm{CO}$ and $\mathrm{Et}_{2} \mathrm{NH}$. Yields of $\alpha$-keto amides are moderate to excellent under suitable reaction conditions. Since the reaction procedure is simple and quite a variety of halides can be used as the starting materials this method provides a new general route to $\alpha$-keto amides.

\section{Applications}

The $\alpha$-keto amides can be hydrolyzed in the presence of base to afford $\alpha$-keto acids which can be used for synthesizing various useful organic compounds. One of promising applications is preparation of $\alpha$-amino acids by transfer amination or by treatment of the $\alpha$-keto acids with primary amines to give imines followed by their hydrogenation.

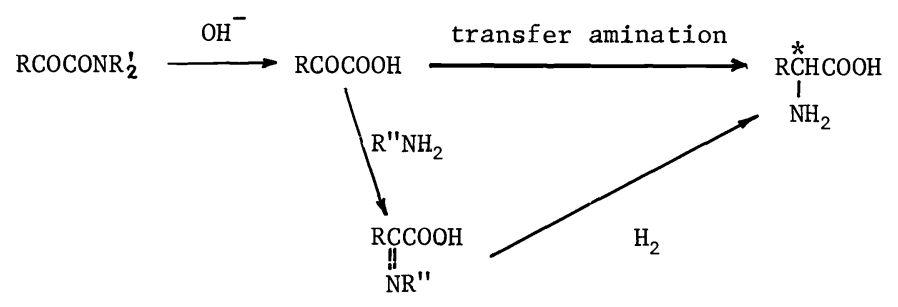

Synthesis of $\alpha$-amino acids from $\alpha$-keto acids is a known process but this route for $\alpha$-amino acid synthesis has not been utilized because of lack of a general route to $\alpha$-keto acids.

Another application is synthesis of $\alpha$-hydroxy acids by hydrogenation of the $\alpha$-keto acids. R-Mandelic acid can be readily obtained on hydrogenation of benzoylformic acid with aid of a yeast.

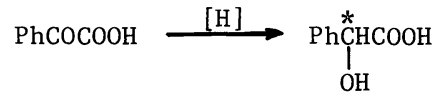


Furthermore, the double carbonylation products can be used for synthesis of heterocyclic compounds. Indole and quinoline derivatives can be prepared by the following routes.

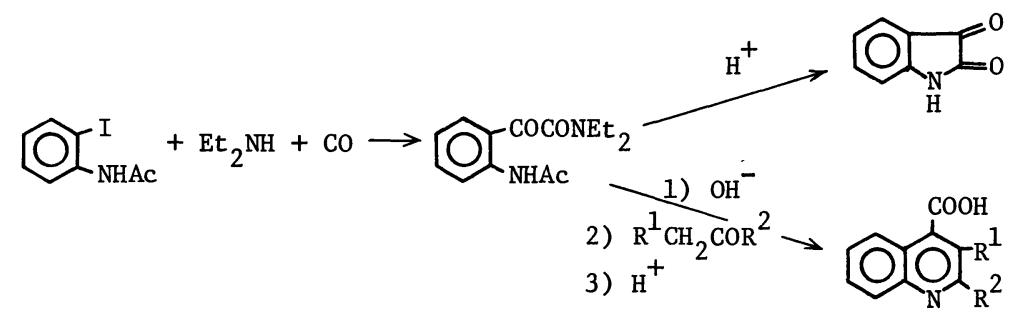

\section{Factors influencing the double carbonylation reactions}

Yields of $\alpha$-keto amides are influenced by various factors including the nature of catalyst, substrate (organic moiety in the aryl halides as well as the kind of halogen atom), amine, CO pressure, solvent, and temperature.

TABLE 1. Palladium-catalyzed double carbonylation of organic halides in the presence of $\mathrm{Et}_{2} \mathrm{NH}$.

\begin{tabular}{|c|c|c|c|c|c|c|}
\hline \multirow{2}{*}{$\mathrm{RX}$} & \multirow{2}{*}{ Catalyst $^{\text {a) }}$} & \multirow{2}{*}{$\begin{array}{c}\left.\mathrm{Co}^{\mathrm{b}}\right) \\
(\mathrm{atm})\end{array}$} & \multirow{2}{*}{$\begin{array}{l}\text { Temp. } \\
\left({ }^{\circ} \mathrm{C}\right)\end{array}$} & \multirow{2}{*}{$\begin{array}{l}\text { Time } \\
\text { (h) }\end{array}$} & \multicolumn{2}{|c|}{ Yield $(\% / R X)^{c)}$} \\
\hline & & & & & $\alpha$-keto amide & amide \\
\hline & A & 50 & 80 & 1.75 & 98 & 2 \\
\hline & A & 50 & 80 & 2 & 96 & 4 \\
\hline & A & 50 & 80 & 0.75 & 91 & 9 \\
\hline & A & 50 & 80 & 1 & 77 & 23 \\
\hline & A & 10 & 100 & 210 & 67 & 15 \\
\hline & A & 10 & 100 & 50 & 72 & 8 \\
\hline & A & 10 & 60 & 72 & 83 & 17 \\
\hline & A & 10 & 100 & 50 & 78 & 17 \\
\hline$-\mathrm{Br}$ & A & 10 & 80 & 90 & 55 & 45 \\
\hline $\mathrm{PhCH}_{2} \mathrm{Cl}$ & A & 10 & 100 & 50 & 3 & 16 \\
\hline $\begin{array}{l}\mathrm{PhCH}=\mathrm{CHBr} \\
(\mathrm{Z} / \mathrm{E}=1 / 6.5)\end{array}$ & B & 50 & 50 & 67 & $\begin{array}{l}70 \\
(\mathrm{E})\end{array}$ & $\begin{array}{c}30 \\
(Z / E=1 / 9.9)\end{array}$ \\
\hline $\begin{array}{c}\mathrm{PhCH}=\mathrm{CHI} \\
(\mathrm{E})\end{array}$ & $\mathrm{C}$ & 70 & 25 & 70 & $\begin{array}{l}93 \\
(\mathrm{E})\end{array}$ & $\begin{array}{c}7 \\
(E)\end{array}$ \\
\hline $\mathrm{Ph}_{2} \mathrm{C}=\mathrm{CHBr}$ & B & 40 & 80 & 18 & 44 & 56 \\
\hline
\end{tabular}

a) 1 or 2 mol\% of palladium catalyst per $\mathrm{RX}$ was used. $\mathrm{A}, \mathrm{PdCl}_{2}\left(\mathrm{PMePh}_{2}\right)_{2}$; $\mathrm{B}, \mathrm{PdCl}_{2}\left(\mathrm{Ph}_{2} \mathrm{PCH}_{2} \mathrm{CH}_{2} \mathrm{CH}_{2} \mathrm{CH}_{2} \mathrm{PPh}_{2}\right) ; \mathrm{C}, \mathrm{PdMe}_{2}\left(\mathrm{PMePh}_{2}\right)_{2}$.

b) Initial value at room temperature.

c) Determined by means of GLC. 
Among various transition metal complexes examined palladium complexes having tertiary phosphine ligands have been found most effective. As the tertiary phosphine ligands both unidentate and bidentate phosphines are effective. The best yield can be obtained when a suitable balance is achieved in the coordinating ability of the tertiary phosphine ligand; namely, neither too strongly coordinating ligand nor too weakly bonding one is suitable for obtaining $\alpha$-keto amide in the highest yield. In the conversion of phenyl bromide to phenylglyoxylamide in the presence of diethylamine under CO pressure, diphenylmethylphosphine and 1,4-bis (diphenylphosphino)butane (dppb) were found to be the most suitable ligands. Tertiary phosphine-coordinated palladium halides are catalytically as effective as organopalladium complexes serving as catalyst precursors.

The reactivity of phenyl halide decreases in the order $\mathrm{PhI}>\mathrm{PhBr}>\mathrm{PhCl}$. Phenyl chloride is so unreactive that it did not give $\alpha$-keto amide even at $200^{\circ} \mathrm{C}$. The reactivity order

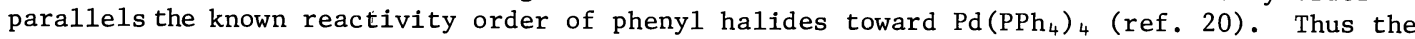
reactivity order in the catalytic double carbonylation process most likely reflects the ease of oxidative addition of phneyl halides to Pd(0) species. Introduction of an electronwithdrawing group into the para position of phenyl bromide causes increase in the reactivity of phenyl bromide at the expense of selectivity for $\alpha$-keto amide formation. A similar trend has been observed for double carbonylation of para-substituted phenyl iodides.

Examination of the effect of CO pressure and concentrations of phenyl halides on the double carbonylation rate indicated that oxidative addition of phenyl bromide constitutes the rate-determining step in the double carbonylation of phenyl bromide whereas the ratedetermining step in the double carbonylation of phenyl iodide is associated with the later stage than the oxidative addition of phenyl iodide to the $\mathrm{Pd}(0)$ species.

Amines used in the double carbonylation have a profound influence on the yields of $\alpha$-keto amides and amides. Amines suitable for the double carbonylation are basic secondary amines of moderate steric bulkiness. Primary amines are not suitable since they react with the produced $\alpha$-keto amides forming imines, although a very bulky primary amine such as tertbutylamine can be employed because of its inertness to the $\alpha$-keto amide. Among secondary amines of high basicities $\left(\mathrm{pK}_{\mathrm{b}}=\mathrm{ca}\right.$. 3) very bulky amines are inactive whereas too compact amines give poor selectivities for the $\alpha$-keto amide formation. Comparison of the relative yields of $\alpha$-keto amides in the reaction of phenyl bromide with $C O$ and a series of secondary amines catalyzed by $\mathrm{PdCl}_{2}\left(\mathrm{PPh}_{2} \mathrm{Me}\right)_{2}$ revealed the following selectivity order (\% $\alpha$-ketoamide formed/total carbonylation product) $\mathrm{Pr}_{2} \mathrm{NH}(91)>\mathrm{Et}_{2} \mathrm{NH}(75)>$ hexamethyleneimine $(24)>$ piperidine (21) > Me ${ }_{2} \mathrm{NH}(7)>$ pyrrolidine (0).

\section{Mechanism}

On the basis of the results obtained in the catalytic reactions of aryl halides with $c 0$ and secondary amines as well as those in stoichiometric reactions of organopalladium complexes that are likely involved in the catalytic process (ref. 21,22) a reaction mechanism represented by Scheme II has been proposed (ref. 23).

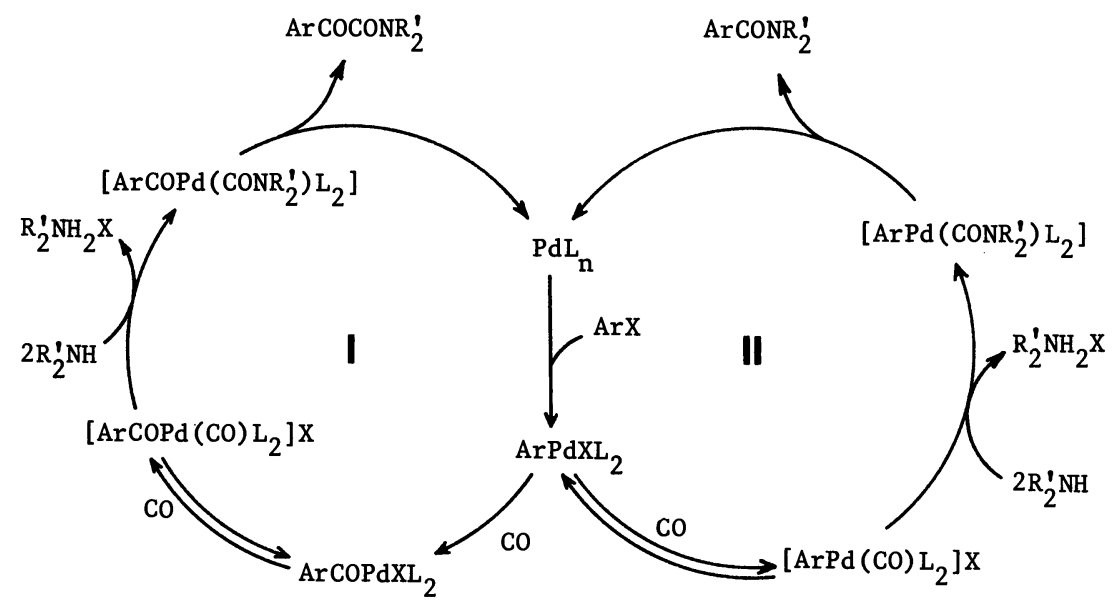

Scheme II Proposed mechanism for the catalytic double carbonylation and monocarbonylation of aryl halides catalyzed by tertiary phosphine-coordinated palladium complexes.

Scheme II comprises two catalytic cycles, one for producing $\alpha$-keto amide (Cycle I) and the other for amide synthesis (Cycle II). Oxidative addition of aryl halide to a zero valent palladium species is common to the both cycles. This process affording trans- $\operatorname{PdAr}(\mathrm{X}) \mathrm{L}_{2}$ is well known. 
In cycle I that catalytically produces the $\alpha$-keto amide, $\operatorname{ArPdXL} 2$ undergoes $C 0$ insertion to give an acylpalladium complex $\mathrm{ArCOPdXL}_{2}$. In fact the acylpalladium complex can be isolated by treating $\mathrm{ArPdXL}_{2}$ with $\mathrm{CO}$. Further coordination of $\mathrm{CO}$ to the acyl complex gives an ionic CO-coordinated acylpalladium complex $\left[\operatorname{ArCOPd}(\mathrm{CO}) \mathrm{L}_{2}\right]^{+} \mathrm{X}^{-}$. Examination of the IR spectrum of a solution containing $\mathrm{ArCOPdL}_{2} \mathrm{I}$ under $\mathrm{CO}$ pressure has revealed the formation of such a COcoordinated complex and that generation of the CO-coordinated ionic complex is favored in protic solvents. Attack of amine $\mathrm{R}_{2}^{i} \mathrm{NH}$ on the coordinated $\mathrm{CO}$ ligand and liberation of $\mathrm{R}_{2}^{\prime} \mathrm{NH}_{2} \mathrm{X}$ affords an acyl-carbamoylpalladium complex $\operatorname{ArCOPd}\left(\mathrm{CONR}_{2}^{\prime}\right) \mathrm{L}_{2}$ which reductively eliminates $\alpha$-keto amide with regenation of $\operatorname{Pd}(0)$ species that further carries the catalytic cycle. In fact treatment of $\left[\operatorname{ArCOPd}(\mathrm{CO})\left(\mathrm{PMePh}_{2}\right)_{2}\right] \mathrm{ClO}_{4}$ with secondary amines readily produces $\alpha$-keto amides. It was further confirmed that treatment of the platinum analogue $\left[\mathrm{PhCOPt}(\mathrm{CO})\left(\mathrm{PPh}_{3}\right)_{2}\right] \mathrm{ClO}_{4}$ with $\mathrm{Me}_{2} \mathrm{NH}$ afforded trans-PhCOPt $\left(\mathrm{CONMe}_{2}\right)\left(\mathrm{PPh}_{3}\right)_{2}$. Thus feasibility of the catalytic cycle I has been established on the basis of studies on each fundamental process using well-characterized organopalladium compounds.

The mechanism represented in Cycle II somewhat differs from the generally accepted mechanism to account for the monocarbonylation process where nucleophilic attack by amine on the acylpalladium complex was assumed. Instead we favor the mechanism shown in Cycle II where first CO coordination to the arylpalladium complex to give an ionic C0-coordinated arylpalladium species is involved. Subsequent nucleophilic attack by amine on the coordinated CO gives aryl-carbamoylpalladium complex which reductively eliminates amide as the monocarbonylation product with regeneration of a $\mathrm{Pd}(0)$ species. The direct attack of amine on the acylpalladium complex may be taking place in a slow stoichiometric process but the mechanism represented in Cycle II accounts for the bulk of experimental evidence much more reasonably.

The relative rate of $\alpha$-keto amide formation by treating $\mathrm{PhCOPdI}\left(\mathrm{PMePh}_{2}\right)_{2}$ with a series of secondary amines was found to be in the following order:

\begin{tabular}{|c|c|c|c|c|c|c|}
\hline Amine & $\mathrm{Pr}_{2} \mathrm{NH}$ & $\mathrm{t}_{2} \mathrm{NH}$ & & $\mathrm{Me}_{2} \mathrm{NH}$ & $\left(\mathrm{H}_{2}\right)_{6}$ & \\
\hline Relative rate & 0.75 & 1 & 11 & 21 & 26 & 98 \\
\hline
\end{tabular}

It can be seen that the more compact amine reacts with the benzoylpalladium complex at higher rate and the reactivity order of amines is reverse to the selectivity order for the catalytic $\alpha$-keto amide formation.

The similar trend has been observed in the reactions of $\mathrm{CO}$ and amines with $\mathrm{PhCOPdIL}_{2}$ having other tertiary phosphines than $\mathrm{PMePh}_{2}$. The plot of logarithms of the relative rates of $\alpha$-keto amide formation in the reactions of $\mathrm{PhCOPdI}\left(\mathrm{PMePh}_{2}\right)_{2}$ versus the logarithms of the similar reaction rates of $\mathrm{PhCOPdI}\left(\mathrm{PPh}_{3}\right)_{2}$ in reactions with $\mathrm{CO}$ and a variety of amines showed an excellent linear relationship as shown in Fig. 1.

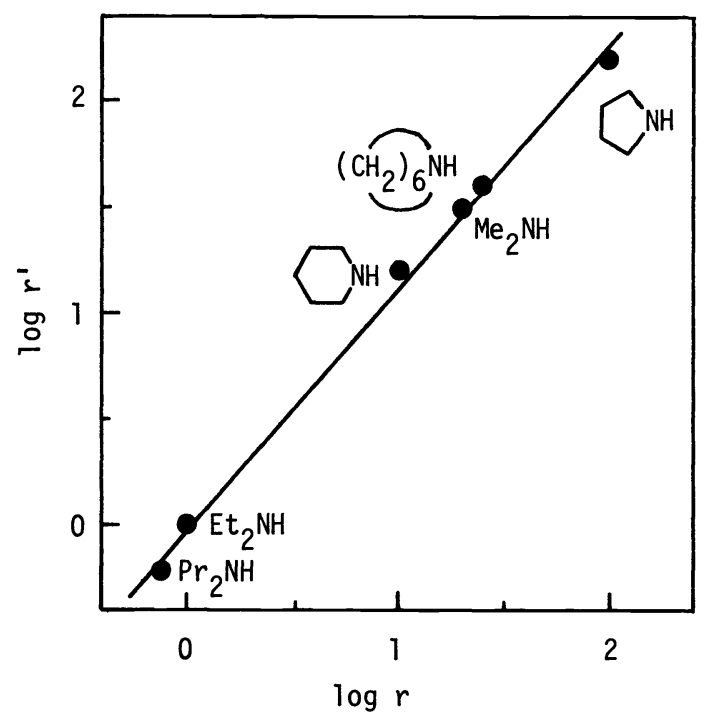

Fig. 1. Correlation of relative reactivities of amines toward trans-Pd(COPh) I $\left(\mathrm{PMePh}_{2}\right)_{2}(\mathrm{r})$ and trans-Pd$(\mathrm{COPh}) \overline{\mathrm{I}\left(\mathrm{PPh}_{3}\right)_{2}}\left(\mathrm{r}^{\prime}\right)$ under $\mathrm{CO}$ pressure. 
Although the relationship represented in Fig. 1 probably reflects the relative rates of formation of the carbamoyl group by attack of amines on the coordinated Co ligand, the reaction rates may include other factors, which are not directly associated with the reactive rate of nucleophilic attack, since the rates have been observed by measuring the rates of $\alpha$-keto amide formation. Therefore, for obtaining more direct information on the rates of attack of amines on metal-coordinate $C O$ ligand, reaction rates for the following reactions of CO-coordinated platinum complex with amines were measured and compared with the rates of $\alpha$-keto amide formation from $\mathrm{PhCOPdI}\left(\mathrm{PMePh}_{2}\right)_{2}$ with $\mathrm{CO}$ and amines.

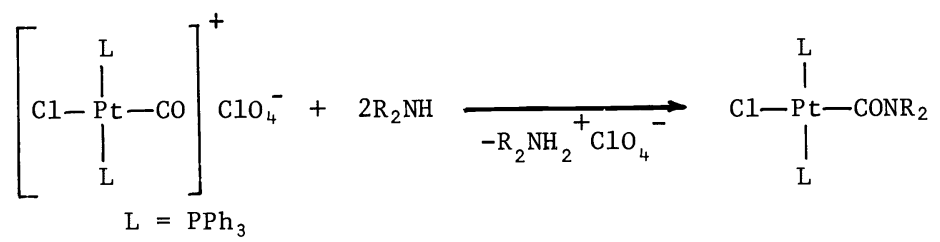

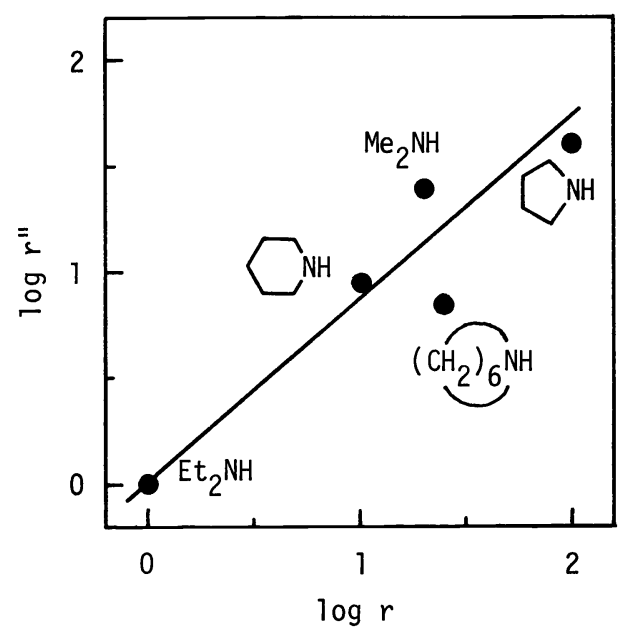

Fig. 2. Correlation of relative reactivities of amines toward trans-Pd $(\mathrm{COPh}) \mathrm{I}\left(\mathrm{PMePh}_{2}\right)_{2}$ under $\mathrm{CO}$ pressure and trans-[ $\left[\overline{\mathrm{Pt}(\mathrm{CO})} \mathrm{Cl}\left(\mathrm{PPh}_{3}\right)_{2}\right] \mathrm{ClO}_{4}$ ( $\left.\mathrm{r}^{\prime \prime}\right)$.

The results shown in Fig. 2 indicates that the relative rates of $\alpha$-keto amide formation from $\mathrm{PhCOPdI}\left(\mathrm{PMePh}_{2}\right)_{2}, \mathrm{CO}$ and various amines are correlated with the rates of attack of the amines on the platinum-coordinated CO ligand.

These results are in agreement with mechanisms represented in Scheme II. The selectivity for the $\alpha$-keto amide formation can be expressed by the following formula,

$$
\text { Selectivity }(\%)=\frac{r_{1}}{r_{1}+r_{2}} \times 100
$$

where $r_{1}$ stands for the rate of $C 0$ insertion into the $P d-C$ bond in $A r P d X L_{2}$ and $r_{2}$ the rate of attack of amine on the $\mathrm{CO}$ ligand in $\operatorname{ArPd}(\mathrm{CO}) \mathrm{XL}_{2}$. The CO insertion rate $\mathrm{r}_{1}$ probably does not vary depending on the nature of amines and the selectivity is thus determined principally by the relative rate of attack of amines on the coordinated $\mathrm{CO}$ in $\mathrm{PhPd}(\mathrm{CO}) \mathrm{L}_{2} \mathrm{X}$ type species. Selectivity values calculated with an approximation that the rate of nucleophilic attack by amine on the coordinated $\mathrm{CO}$ in $\operatorname{ArPd}(\mathrm{CO}) \mathrm{XL}_{2}$ is the same as that on the coordinated $\mathrm{CO}$ in $\operatorname{ArCOPd}(\mathrm{CO}) \mathrm{XL}_{2}$ showed a reasonable agreement with the experimental selectivity values.

\section{Synthesis of $\alpha$-keto esters by double carbonylation using alcohols}

Catalytic double carbonylation of organic halides using alcohols can be achieved albeit with some difficulty (ref. 24). Phenyl iodide has been converted into $\alpha$-keto ester using $\mathrm{Pd}\left(\mathrm{PCy}_{3}\right)_{2} \mathrm{Cl}_{2}$ with the selectivity of ca. $70 \%$ in the presence of 2 -butanol and $\mathrm{NEt}_{3}$. However, the reaction rate was much slower than that with secondary amines and higher Co pressure was needed. Substituted phenyl iodides, 2-iodothiophene and 2-iodoquinoline also have been double-carbonylated with good to moderate selectivities as shown in Table 2 . The reaction mechanisms for giving $\alpha$-keto esters and esters are considered to be similar to Scheme II. 
TABLE 2. Double carbonylation of aryl iodides and 2-butanol catalyzed by $\mathrm{PdCl}_{2}\left(\mathrm{PCy}_{3}\right)_{2}$ in $\mathrm{CH}_{2} \mathrm{Cl}_{2}$.

\begin{tabular}{|c|c|c|c|c|c|c|}
\hline \multirow[t]{7}{*}{$\mathrm{RX}$} & $\begin{array}{c}\left.\mathrm{CO}^{\mathrm{a}}\right) \\
(\mathrm{atm})\end{array}$ & $\begin{array}{l}\text { Temp. } \\
\left({ }^{\circ} \mathrm{C}\right)\end{array}$ & $\begin{array}{l}\text { Time } \\
\text { (h) }\end{array}$ & $\frac{\text { Selectivity }}{\alpha-\text { keto ester }}$ & $\frac{(\%)}{\text { ester }}$ & $\begin{array}{l}\text { Conversion } \\
\text { of } \mathrm{RX}(\%)\end{array}$ \\
\hline & 70 & 70 & 96 & 66 & 34 & 74 \\
\hline & 70 & 70 & 72 & 69 & 31 & 82 \\
\hline & 70 & 70 & 72 & 63 & 37 & 75 \\
\hline & 70 & 70 & 72 & 48 & 52 & 97 \\
\hline & 70 & 70 & 96 & 64 & 36 & 95 \\
\hline & 70 & 70 & 72 & 22 & 78 & 100 \\
\hline
\end{tabular}

Reactions were carried out using aryl iodide $(\approx 5 \mathrm{mmol}), 2$-butanol (11 mmol), $\mathrm{Et}_{3} \mathrm{~N}(7.6 \mathrm{mmol})$, and $\mathrm{PdCl}_{2}\left(\mathrm{PCy}_{3}\right)_{2}$ catalyst $(0.1 \mathrm{mmol})$ in $\mathrm{CH}_{2} \mathrm{Cl}_{2}(2 \mathrm{~mL})$. a) Initial pressure measured at room temperature。

Although catalytic synthesis of $\alpha$-keto esters are preparatively more attractive than that of $\alpha$-keto amides, some of which resist to hydrolysis, the conditions for selectively synthesizing the $\alpha$-keto esters seem to be limited.

\section{$\alpha$-keto amide synthesis using alkenes}

Although the present method for $\alpha$-keto amide synthesis is applicable to aryl and alkenyl halides, it is not suitable for alkyl halides since they react with secondary amines. Stoichiometric double carbonylation involving the following reaction sequence has been developed.

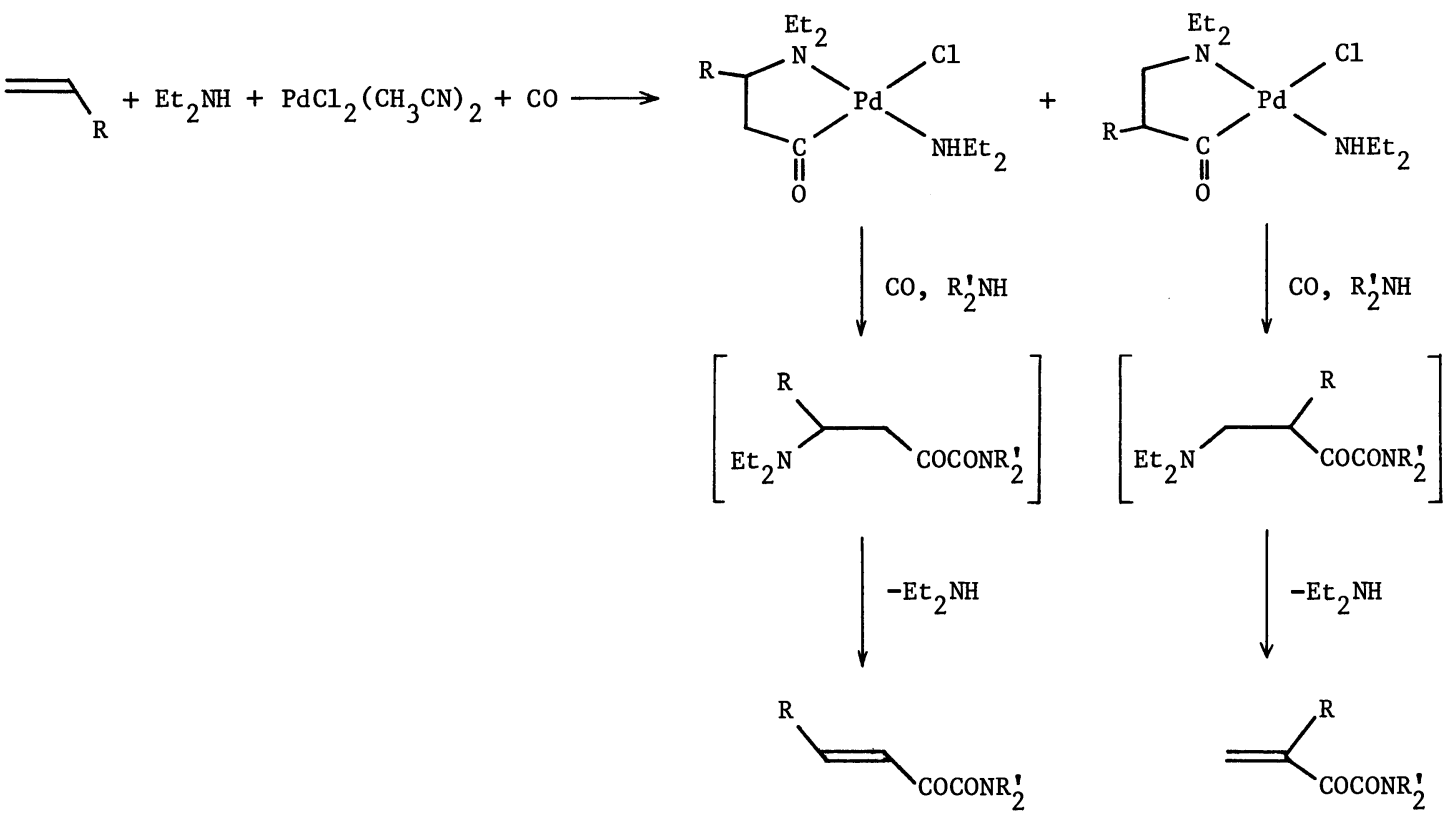




\section{REFERENCES}

1. (a) C. M. Lukehart, Fundamental Transition Metal Organometallic Chemistry, Brooks/Cole, Monterey, 1985; (b) J. P. Collman and L. S. Hegedus, Principles and Applications of Organotransition Metal Chemistry, University Science Books, Mill Valley, 1980; (c) J. K. Kochi, Organometallic Mechanisms and Catalysis, Academic Press, New York, 1978; (d) J. Tsuji, Organic Synthesis with Palladium Compounds, Springer-Verlag, Berlin, 1980; (e) A. Yamamoto, Organotransition Metal Chemistry-Fundamental Concepts and Applications-, John Wiley, New York, in press.

2. A. Yamamoto, T. Yamamoto, S. Komiya, and F. Ozawa, Pure \& App1. Chem., 56, 1621 (1984).

3. (a) A. Yamamoto and S. Ikeda, J. Am. Chem. Soc., 89, 5989 (1967); (b) T. Yamamoto, A. Yamamoto, and S. Ikeda, J. Am. Chem. Soc., 93, 3350, 3360 (1971).

4. S. Komiya, Y. Abe, A. Yamamoto, and T. Yamamoto, Organometallics, 2, 1466 (1983).

5. K. Tatsumi, A. Nakamura, S. Komiya, A. Yamamoto, and T. Yamamoto, J. Am. Chem. Soc., 106, 8181 (1984).

6. (a) A. Gillie and J. K. Stille, J. Am. Chem. Soc., 102, 4933 (1980); (b) M. Loar and J. K. Stille, ibid., 103, 4174 (1981); (c) A. Moravskiy and J. K. Stille, ibid., 103, 4182 (1981).

7. F. Ozawa, T. Ito, Y. Nakamura, and A. Yamamoto, Bul1. Chem. Soc. Jpn., 54, 1868 (1981).

8. K. Tatsumi, R. Hoffmann, A. Yamamoto, and J. K. Stille, Bull. Chem. Soc. Jpn., 54,1857 (1981).

9. F. Ozawa, T. Ito, and A. Yamamoto, J. Am. Chem. Soc., 102, 6457 (1980).

10. T. Kohara, S. Komiya, T. Yamamoto, and A. Yamamoto, Chem. Lett., 1513 (1979).

11. T. Yamamoto, T. Kohara, and A. Yamamoto, Bu11. Chem. Soc. Jpn., 54, 2010, 2161 (1981).

12. S. Komiya, A. Yamamoto, and T. Yamamoto, Chem. Lett., 193 (1981).

13. T. Yamamoto, J. Ishizu, T. Kohara, S. Komiya, and A. Yamamoto, J. Am. Chem. Soc., 102, 3758 (1980).

14. T. Yamamoto, 0. Saito, and A. Yamamoto, J. Am. Chem. Soc., 103, 5600 (1981).

15. T. Yamamoto, M. Akimoto, and A. Yamamoto, Chem. Lett., 1725 (1983).

16. S. Komiya, Y. Akai, K. Tanaka, T. Yamamoto, and A. Yamamoto, Organometallics, in press.

17. F. Ozawa and A. Yamamoto, Chem. Lett., 865 (1982).

18. F. Ozawa, H. Soyama, T. Yamamoto, and A. Yamamoto, Tetrahedron Lett., 23, 3383 (1982).

19. T. Kobayashi and M. Tanaka independently developed a similar process, J. Organometal. Chem., 233, C64 (1982)

20. P. F. Fitton and E. A. Rick, J. Organometal. Chem., 28, 287 (1971).

21. F. Ozawa, T. Sugimoto, Y. Yuasa, M. Santra, T. Yamamoto, and A. Yamamoto, Organometallics, 3, 683 (1984).

22. $\bar{F}$. Ozawa, T. Sugimoto, T. Yamamoto, and A. Yamamoto, ibid., 3, 692 (1984).

23. (a) F. Ozawa, H. Soyama, H. Yanagihara, I. Aoyama, H. Takino, K. Izawa, T. Yamamoto, and A. Yamamoto, J. Am. Chem. Soc., in press; (b) F. Ozawa, H. Okamoto, T. Yamamoto, and A. Yamamoto, unpublished results.

24. F. Ozawa, N. Kawasaki, T. Yamamoto, and A. Yamamoto, Chem. Lett., 567 (1985). 